\title{
Government Spending in a Simple Model of Endogeneous Growth
}

\section{Citation}

Barro, Robert J. 1990. Government spending in a simple model of endogeneous growth. Journal of Political Economy 98(S5): 103-125.

\section{Published Version}

doi:10.1086/261726

\section{Permanent link}

http://nrs.harvard.edu/urn-3:HUL.InstRepos:3451296

\section{Terms of Use}

This article was downloaded from Harvard University's DASH repository, and is made available under the terms and conditions applicable to Other Posted Material, as set forth at http:// nrs.harvard.edu/urn-3:HUL.InstRepos:dash.current.terms-of-use\#LAA

\section{Share Your Story}

The Harvard community has made this article openly available.

Please share how this access benefits you. Submit a story.

Accessibility 


\section{Government Spending in a Simple Model of Endogenous Growth}

\section{Robert J. Barro}

Harvard University and National Bureau of Economic Research

One strand of endogenous-growth models assumes constant returns to a broad concept of capital. I extend these models to include taxfinanced government services that affect production or utility. Growth and saving rates fall with an increase in utility-type expenditures; the two rates rise initially with productive government expenditures but subsequently decline. With an income tax, the decentralized choices of growth and saving are "too low," but if the production function is Cobb-Douglas, the optimizing government still satisfies a natural condition for productive efficiency. Empirical evidence across countries supports some of the hypotheses about government and growth.

Recent models of economic growth can generate long-term growth without relying on exogenous changes in technology or population. Some of the models amount to theories of technological progress (Romer 1986; this issue) and others to theories of population change (Becker and Barro 1988). A general feature of these models is the presence of constant or increasing returns in the factors that can be accumulated (Lucas 1988; Romer 1989; Rebelo 1991).

This research is supported by the National Science Foundation and the Bradley Foundation and is part of the National Bureau of Economic Research's project on economic growth. I am grateful for comments from Gary Becker, Fabio Canova, Brad De Long, Daniel Gros, Herschel Grossman, Bob Hall, Ken Judd, Harl Ryder, Steve Slutsky, Juan Jose Suarez, and Larry Summers. I have also benefited from discussions at the National Bureau of Economic Research, Brown University, the University of Florida, and the conference, "The Problem of Development: Exploring Economic Development through Free Enterprise," State University of New York at Buffalo, May 1988 . 
One strand of the literature on endogenous economic growth concerns models in which private and social returns to investment diverge, so that decentralized choices lead to suboptimal rates of saving and economic growth (Arrow 1962; Romer 1986). In this setting private returns to scale may be diminishing, but social returns-which reflect spillovers of knowledge or other externalities-can be constant or increasing. Another line of research involves models without externalities, in which the privately determined choices of saving and growth are Pareto optimal (Rebelo 1991). These models rely on constant returns to private capital, broadly defined to encompass human and nonhuman capital.

The present analysis builds on both aspects of this literature by incorporating a public sector into a simple, constant-returns model of economic growth. Because of familiar externalities associated with public expenditures and taxes, the privately determined values of saving and economic growth may be suboptimal. Hence there are interesting choices about government policies, as well as empirical predictions about the relations among the size of government, the saving rate, and the rate of economic growth.

\section{Endogenous Growth Models with Optimizing Households}

I begin with endogenous growth models that build on constant returns to a broad concept of capital. The representative, infinite-lived household in a closed economy seeks to maximize overall utility, as given by

$$
U=\int_{0}^{\infty} u(c) e^{-\rho t} d t
$$

where $c$ is consumption per person and $\rho>0$ is the constant rate of time preference. Population, which corresponds to the number of workers and consumers, is constant. I use the utility function

$$
u(c)=\frac{c^{1-\sigma}-1}{1-\sigma},
$$

where $\sigma>0$, so that marginal utility has the constant elasticity $-\sigma$.

Each household-producer has access to the production function

$$
y=f(k),
$$

where $y$ is output per worker and $k$ is capital per worker. Each person works a given amount of time; that is, there is no labor-leisure choice. As is well known, the maximization of the representative household's 
overall utility in equation (1) implies that the growth rate of consumption at each point in time is given by

$$
\frac{\dot{c}}{c}=\frac{1}{\sigma} \cdot\left(f^{\prime}-\rho\right),
$$

where $f^{\prime}$ is the marginal product of capital. Instead of assuming diminishing returns $\left(f^{\prime \prime}<0\right)$, I follow Rebelo (1991) by assuming constant returns to a broad concept of capital; that is,

$$
y=A k,
$$

where $A>0$ is the constant net marginal product of capital. ${ }^{1}$

The assumption of constant returns becomes more plausible when capital is viewed broadly to encompass human and nonhuman capital. Human investments include education and training, as well as expenses for having and raising children (Becker and Barro 1988). Of course, human and nonhuman capital need not be perfect substitutes in production. Therefore, production may show roughly constant returns to scale in the two types of capital taken together but diminishing returns in either input separately. The $A k$ production function shown in equation (5) can be modified to distinguish between two types of capital, and the model can be extended, along the lines of Lucas (1988), Rebelo (1991), and Becker, Murphy, and Tamura (this issue), to allow for sectors that produce physical and human capital, respectively. In comparison with the $A k$ model, the main additional results involve transitional dynamics whereby an economy moves from an arbitrary starting ratio of physical to human capital to a steady-state ratio. For studying steady-state growth, however, the important element is constant returns to scale in the factors that can be accumulated-that is, the two types of capital taken together-and not the distinction between the factors.

Substituting $f^{\prime}=A$ into equation (4) yields

$$
\gamma=\frac{\dot{c}}{c}=\frac{1}{\sigma} \cdot(A-\rho),
$$

where the symbol $\gamma$ denotes a per capita growth rate. I assume that the technology is sufficiently productive to ensure positive steadystate growth, but not so productive as to yield unbounded utility. The corresponding inequality conditions are

\footnotetext{
${ }^{1}$ This formulation effectively reverses Solow's (1956) extension of the Harrod (1948)-Domar (1947) model to return to a setting with a fixed capital/output ratio. The formulation differs, however, from the Harrod-Domar model in that saving choices are privately optimal (as in the analyses of Ramsey [1928], Cass [1965], and Koopmans [1965]).
} 


$$
A>\rho>A(1-\sigma) .
$$

The first part implies $\gamma>0$ in equation (6). The second part, which is satisfied automatically if $A>0, \rho>0$, and $\sigma \geq 1$, guarantees that the attainable utility is bounded.

In this model the economy is always at a position of steady-state growth in which all variables-c, $k$, and $y$ - grow at the rate $\gamma$ shown in equation (6). Given an initial capital stock, $k(0)$, the levels of all variables are also determined. ${ }^{2}$ In particular, since net investment equals $\gamma k$, the initial level of consumption is

$$
c(0)=k(0) \cdot(A-\gamma) .
$$

I now modify the analysis to incorporate a public sector. Let $g$ be the quantity of public services provided to each household-producer. I assume that these services are provided without user charges and are not subject to congestion effects (which might arise for highways or some other public services). That is, the model abstracts from externalities associated with the use of public services.

I consider initially the role of public services as an input to private production. It is this productive role that creates a potentially positive linkage between government and growth. Production now exhibits constant returns to scale in $k$ and $g$ together but diminishing returns in $k$ separately. That is, even with a broad concept of private capital, production involves decreasing returns to private inputs if the (complementary) government inputs do not expand in a parallel manner. In a recent empirical study, Aschauer (1988) argues that the services from government infrastructure are particularly important in this context.

Given constant returns to scale, the production function can be written as

$$
y=\Phi(k, g)=k \cdot \phi\left(\frac{g}{k}\right),
$$

where $\Phi$ satisfies the usual conditions for positive and diminishing marginal products, so that $\phi^{\prime}>0$ and $\phi^{\prime \prime}<0 .{ }^{3}$ The variable $k$ is the

\footnotetext{
${ }^{2}$ With a perfect capital market (and given constant returns to scale and no adjustment costs for investment), the scale of a competitive firm would be indeterminate in this model. However, the aggregates of capital stock and investment would be determined.

${ }^{3}$ Arrow and Kurz (1970, chap. 4) assume that public capital, rather than the flow of public services, enters into the production function. Because output can be used for consumption or to augment private or public capital and because the two capital stocks are transferable across the sectors, this difference in specification is not substantive. They assume also that the flow of services from public capital enters into the utility function, a possibility that I analyze later on. Their analysis differs from mine in assuming diminishing returns to scale in private and public capital, given an exogenous
} 
representative producer's quantity of capital, which would correspond to the per capita amount of aggregate capital. I assume that $g$ can be measured correspondingly by the per capita quantity of government purchases of goods and services. In some of the subsequent analysis, I assume that the production function is Cobb-Douglas, so that

$$
\frac{y}{k}=\phi\left(\frac{g}{k}\right)=A \cdot\left(\frac{g}{k}\right)^{\alpha}
$$

where $0<\alpha<1$.

A number of questions arise concerning the specification of public services as an input to production. First, the flow of services need not correspond to government purchases, especially when the government owns capital and the national accounts omit an imputed rental income on public capital in the measure of current purchases. This issue is important for empirical implementation of the model. But conceptually, it is satisfactory to think of the government as doing no production and owning no capital. Then the government just buys a flow of output (including services of highways, sewers, battleships, etc.) from the private sector. These purchased services, which the government makes available to households, correspond to the input that matters for private production in equation (9). As long as the government and the private sector have the same production functions, the results would be the same if the government buys private inputs and does its own production, instead of purchasing only final output from the private sector, as I assume.

A second issue arises if public services are nonrival for the users (as is true, e.g., for the space program). Then it is the total of government purchases, rather than the amount per capita, that matters for each individual. As is well known at least since Samuelson (1954), this element is important for determining the desirable scale of governmental activity. My view is that few actual government services (including, as Thompson [1974] argues, national defense) are nonrival. But the present analysis can be modified to include this aspect of publicness without changing the general nature of the results.

The general idea of including $g$ as a separate argument of the production function is that private inputs, represented by $k$, are not a close substitute for public inputs. Private activity would not readily replace public activity if user charges were difficult to implement, as in the case of such nonexcludable services as national defense and the

amount of labor services (which corresponds to population). Therefore, the per capita growth rate in their model depends in the long run entirely on the exogenous rate of technological progress. 
maintenance of law and order. In other cases, user charges would be undesirable, either because the service is nonrival or because external effects cause private production to be too low (as is sometimes argued for basic education).

I assume that government expenditure is financed contemporaneously by a flat-rate income tax

$$
g=T=\tau y=\tau \cdot k \cdot \phi\left(\frac{g}{k}\right),
$$

where $T$ is government revenue and $\tau$ is the tax rate. I have normalized the number of households to unity so that $g$ corresponds to aggregate expenditures and $T$ to aggregate revenues. Note that equation (11) constrains the government to run a balanced budget. That is, the government can neither finance deficits by issuing debt nor run surpluses by accumulating assets.

The production function in equation (9) implies that the marginal product of capital is

$$
\frac{\partial y}{\partial k}=\phi\left(\frac{g}{k}\right) \cdot\left(1-\phi^{\prime} \cdot \frac{g}{y}\right)=\phi\left(\frac{g}{k}\right) \cdot(1-\eta),
$$

where $\eta$ is the elasticity of $y$ with respect to $g$ (for a given value of $k$ ), so that $0<\eta<1$. Note that the marginal product, $\partial y / \partial k$, is calculated by varying $k$ in equation (9), while holding $g$ fixed. That is, the representative producer assumes that changes in his quantity of capital and output do not lead to any changes in his amount of public services.

Private optimization still leads to a path of consumption that satisfies equation (4), except that $f^{\prime}$ is replaced by the private marginal return to capital. With the presence of a flat-rate income tax at rate $\tau$, this return is $(1-\tau) \cdot(\partial y / \partial k)$, where $\partial y / \partial k$ is given from equation (12). Therefore, the growth rate of consumption is now

$$
\gamma=\frac{\dot{c}}{c}=\frac{1}{\sigma} \cdot\left[(1-\tau) \cdot \phi\left(\frac{g}{k}\right) \cdot(1-\eta)-\rho\right] .
$$

As long as $\tau$ and, hence, $g / y$ are constants-that is, the government sets $g$ and $T$ to grow at the same rate as $y-g / k$ and $\eta$ and therefore the growth rate $\gamma$ will be constants. Accordingly, the dynamics is the same as that for the $A k$ model analyzed before. Consumption starts at some value $c(0)$ and then grows at the constant rate $\gamma$. Similarly, $k$ and $y$ begin at initial values $k(0)$ and $y(0)$ and then grow at the constant rate $\gamma$. The economy has no transitional dynamics and is always in a position of steady-state growth in which all quantities grow at the rate $\gamma$ shown in equation (13).

Given a starting amount of capital, $k(0)$, the levels of all variables 
are again determined. In particular, the initial quantity of consumption is

$$
c(0)=k(0) \cdot\left[(1-\tau) \cdot \phi\left(\frac{g}{k}\right)-\gamma\right],
$$

where $\gamma$ is given in equation (13). The first term inside the brackets of equation (14) corresponds to $y(0)-g(0)$, and the second term to initial investment, $\dot{k}(0)$.

Different sizes of governments - that is, different values for $g / y$ and $\tau$-have two effects on the growth rate, $\gamma$, in equation (13). An increase in $\tau$ reduces $\gamma$, but an increase in $g / y$ raises $\partial y / \partial k$, which raises $\gamma$. Typically, the second force dominates when the government is small, and the first force dominates when the government is large. A simple example is the Cobb-Douglas technology, in which $\eta$-the elasticity of $y$ with respect to $g$-is constant. In this case, $\eta=\alpha$, where $0<\alpha<1$ in equation (10). The conditions $\tau=g / y$ and $g / k=(g / y) \cdot \phi(g / k)$ imply that the derivative of $\gamma$ with respect to $g / y$ is (when $\eta$ is constant)

$$
\frac{d \gamma}{d(g / y)}=\frac{1}{\sigma} \cdot \phi\left(\frac{g}{k}\right) \cdot\left(\phi^{\prime}-1\right)
$$

Hence the growth rate increases with $g / y$ if $g / k$ is small enough so that $\phi^{\prime}>1$ and declines with $g / y$ if $g / k$ is large enough so that $\phi^{\prime}<1$. With a Cobb-Douglas technology, the size of government that maximizes the growth rate corresponds to the natural condition for productive efficiency: $\phi^{\prime}=1$. Since $\alpha=\eta=\phi^{\prime} \cdot(g / y)$, it follows that $\alpha=g / y=\tau$. Roughly speaking, to maximize the growth rate, the government sets its share of gross national product, $g / y$, to equal the share it would get if public services were a competitively supplied input of production.

The solid curve in figure 1 shows the relation between the growth rate, $\gamma$, and the tax and expenditure rate, $\tau=g / y$, for the CobbDouglas case. (The graph assumes specific numerical values for the parameters $\alpha, A, \rho$, and $\sigma$, solely for illustrative purposes.) The growth rate is positive over some range if the economy is sufficiently productive relative to the rate of time preference. The condition for a range with positive growth (which generalizes the condition $A>\rho$ from the $A k$ model $)$ is $A^{1 /(1-\alpha)} \cdot(1-\alpha)^{2} \cdot \alpha^{\alpha /(1-\alpha)}>\rho$. Also, as before, I assume that the economy is not so productive that it allows the attained utility to become unbounded; the condition here is $\rho>A^{1 /(1-\alpha)} \cdot(1-\sigma)(1-\alpha)^{2} \cdot \alpha^{\alpha /(1-\alpha)}$, which must hold if $A>0$, $\rho>0$, and $\sigma \geq 1$.

If the production function is not Cobb-Douglas, the dependence of $\eta$ on $g / k$ in equation (13) affects the results. The condition for maximizing the growth rate can be expressed in terms of the elasticity of 


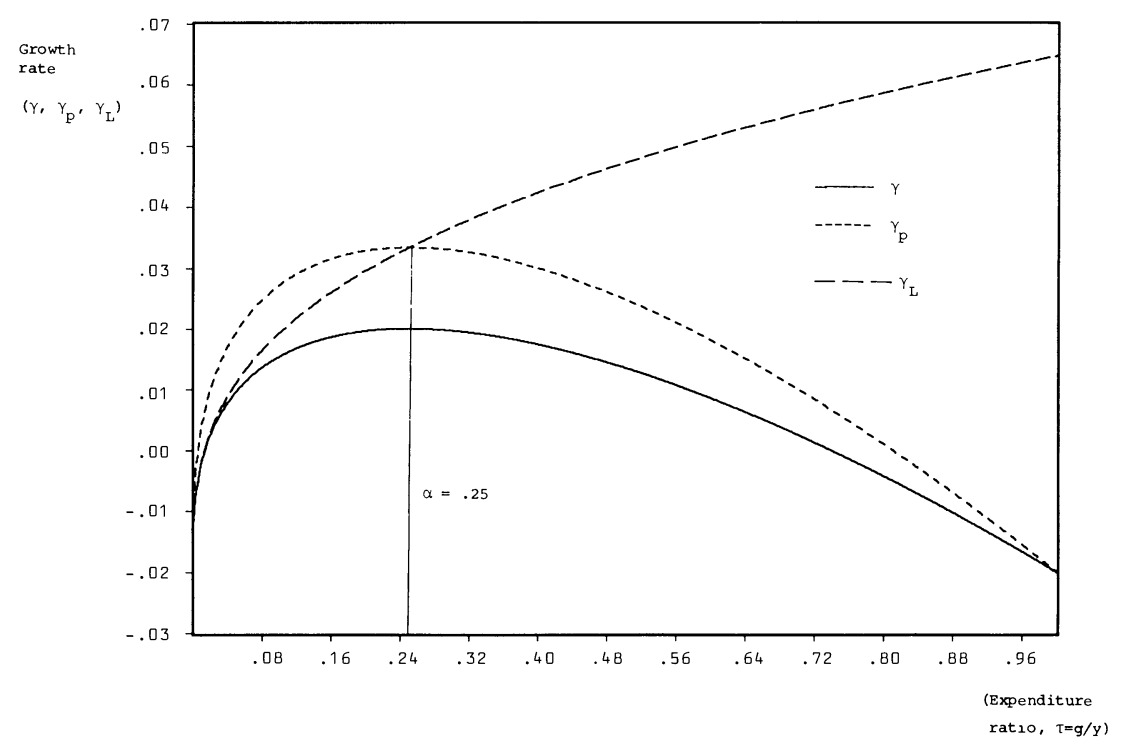

FIG. 1.-Growth rate in three environments. The curves assume Cobb-Douglas technology. $\gamma$ is from eq. (13), $\gamma_{p}$ from eq. (20), and $\gamma_{L}$ from eq. (22). Parameter values are $\sigma=1, \alpha=.25, \rho=.02$, and $A^{1 / \alpha}=.113$. These values imply that the maximum of $\gamma$ is .02 .

substitution between the factors $g$ and $k$. At the point of maximal growth, the marginal product of public services, $\phi^{\prime}$, turns out to be above or below unity as the magnitude of the elasticity of substitution (at the point of maximal growth) is above or below one.

The saving rate is given by

$$
s=\frac{\dot{k}}{y}=\frac{\dot{k}}{k} \cdot \frac{k}{y}=\frac{\gamma}{\phi(g / k)},
$$

where $\gamma$ is given in equation (13). The solid curve in figure 2 is a graph of $s$ versus $\tau=g / y$ for the case of a Cobb-Douglas technology. Because $k / y$ declines with $g / y$, the saving rate peaks before the growth rate. That is, a value $\tau=g / y<\alpha$ (corresponding to $\phi^{\prime}>1$ ) would maximize $s$ in the Cobb-Douglas case.

There is no reason for the government to maximize $\gamma$ or $s$ per se. For a benevolent government, the appropriate objective in this model is to maximize the utility attained by the representative household. Because the economy is always in a position of steady-state growth, it is straightforward to compute the attained utility, as long as $\tau=g / y$ is constant over time. With $\gamma$ constant, the integral in equation (1) can be simplified to yield (aside from a constant) 


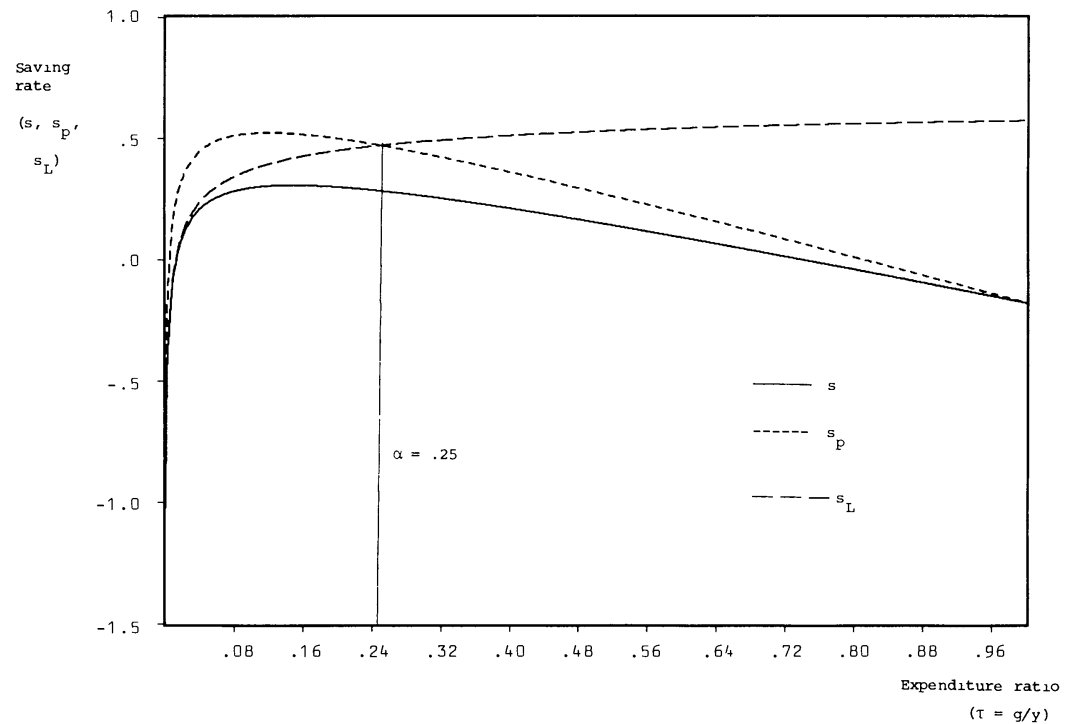

FIG. 2.-Saving rate in three environments. The curves assume Cobb-Douglas technology. $s$ is from eq. (16), $s_{p}=\gamma_{p} \cdot(k / y)$, and $s_{L}=\gamma_{L} \cdot(k / y)$, where $\gamma_{p}$ is from eq. (20) and $\gamma_{L}$ from eq. (22). Parameter values are given in fig. 1 .

$$
U=\frac{[c(0)]^{1-\sigma}}{(1-\sigma)[\rho-\gamma(1-\sigma)]} .
$$

The condition that utility be bounded, mentioned before, ensures that $\rho>\gamma(1-\sigma)$.

Equations (13) and (14) determine $\gamma$ and $c(0)$, respectively, as functions of $\tau=g / y$. Hence, these formulas can be used to determine the share of government in gross domestic product that maximizes $U$ in equation (17). To see the nature of the results, note that equations (13) and (14) imply that $c(0)$ can be written as

$$
c(0)=\frac{k(0)}{1-\eta} \cdot[\rho+\gamma \cdot(\sigma+\alpha-1)] .
$$

Substituting into equation (17) yields a relation between $U$ and $\gamma$ :

$$
U=\left[\frac{k(0)}{1-\eta}\right]^{1-\sigma} \cdot\left\{\frac{\rho+\gamma(\eta+\sigma-1)}{(1-\sigma)[\rho-\gamma(1-\sigma)]}\right\}^{1-\sigma} .
$$

If $\eta$ is constant (with $0<\eta<1$ ), it can be shown that the effect of $\gamma$ on $U$ in equation (19) is positive for all values of $\sigma>0$, as long as utility is bounded, so that $\rho>\gamma(1-\sigma)$. (This result applies although an increase in $\gamma$ need not raise $c(0)$ in eq. [18].) Therefore, if $\eta$ is con- 
stant, the maximization of $U$ corresponds to the maximization of $\gamma$. It follows that the productive-efficiency condition, $\phi^{\prime}=1$ (and, correspondingly, $\tau=g / y=\alpha$ ), determines the relative size of government that maximizes utility if the technology is Cobb-Douglas.

The conclusions would again be modified if the production function is not Cobb-Douglas. The relative size of government that maximizes utility turns out to exceed the value that maximizes the growth rate (i.e., $\partial \gamma / \partial[g / y]<0$ applies) if and only if the magnitude of the elasticity of substitution between $g$ and $k$ is greater than unity.

\section{A Planning Problem for the Government}

The results on the size of government in the previous section are solutions to second-best policy problems. Because of familiar externalities implied by public expenditures and taxation, the decentralized choices of saving turn out to generate outcomes that are not Pareto optimal. In fact, the departures from Pareto optimality are analogous to those in the Arrow (1962)-Romer (1986) learning-bydoing models, which relied on the public-goods nature of privately created knowledge.

The easiest way to assess the external effects is to compare the decentralized outcomes with those from an unrealistic planning problem. Suppose that the government chooses a constant expenditure ratio, $g / y$, and can then dictate each household's choices for consumption over time. (It is straightforward to show that a constant $g / y$ is optimal in this planning problem.) Given a value of $g / y$-which, for the moment, I treat as arbitrary - the government picks the consumption path to maximize the representative household's attained utility, where the expression for utility is again given in equations (1) and (2). The resulting condition for the planned growth rate of consumption is

$$
\gamma_{p}=\frac{\dot{c}}{c}=\frac{1}{\sigma} \cdot\left[\left(1-\frac{g}{y}\right) \cdot \phi\left(\frac{g}{k}\right)-\rho\right] .
$$

The term inside the brackets and to the left of the minus sign is the social marginal return on capital, given that the expenditure ratio, $g / y$, is constant. Note that, to maintain $g / y$, an increase in $y$ by one unit requires an increase in $g$ by $g / y$ units. Since the increase in $g$ comes out of the current output stream, the term $\phi(g / k)$, which is the effect of $k$ on $y$, is adjusted by the factor $1-(g / y)$ to calculate the social return on capital.

The condition $g / k=(g / y) \cdot \phi(g / k)$ implies that the derivative of $\gamma_{p}$ from equation (20) with respect to $g / y$ is 


$$
\frac{d \gamma_{p}}{d(g / y)}=\frac{\phi(g / k) \cdot\left(\phi^{\prime}-1\right)}{\sigma(1-\eta)} .
$$

Because $0<\eta<1$, the condition $\phi^{\prime}=1$ corresponds to maximum growth irrespective of the form of the production function. That is, under planning, the productive-efficiency condition for $g$ must hold. It can also be shown that maximizing growth corresponds to maximizing utility in the planning case. Hence, the optimizing planner sets $g / y$ so that $\phi^{\prime}=1$, regardless of the form of the production function.

In equation (13), the expression within the brackets and to the left of the minus sign is the private marginal return on capital, $(1-\tau) \cdot$ $(\partial y / \partial k)$. In contrast, as noted before, the corresponding term in equation (20) is the social marginal return on capital. Hence, with a proportional income tax at rate $\tau=g / y$, the difference between the private choice in equation (13) and the planning solution in equation (20) is the presence of the term $1-\eta$ in the former. Thus it is clear that $\gamma_{p}$ exceeds $\gamma$ for all values of $g / y=\tau$. Because of the income tax, the decentralized choices of consumption and saving lead to too little growth.

The dotted curve in figure 1 shows how $g / y$ affects the planning growth rate, $\gamma_{p}$, for the case of a Cobb-Douglas technology. (The corresponding saving rate appears in fig. 2.) Since the decentralized growth rate $\gamma$ in equation (13) differs from the planning growth rate $\gamma_{p}$ in equation (20) only by the presence of the term $1-\eta$, it followsif $\eta$ is constant-that the shape of the graph of $\gamma_{p}$ versus $g / y$ is the same as that of $\gamma$. Thus both curves peak at the point at which $\phi^{\prime}=1$ and $g / y=\alpha$. Although growth is too low in the decentralized case, with a Cobb-Douglas production function, the value of $g / y$ that maximizes growth (and utility) is the same as that in the planning optimum.

It is natural to consider whether the command optimum can be implemented by replacing the income tax with a lump-sum tax in an environment of decentralized households. (In this model, which lacks a labor-leisure choice, a consumption tax would be equivalent to a lump-sum tax.) With lump-sum taxes, the private marginal return on capital is $\partial y / \partial k$ rather than $(1-\tau) \cdot(\partial y / \partial k)$. Therefore, instead of equation (13), optimizing households would choose the growth rate of consumption

$$
\gamma_{L}=\frac{\dot{c}}{c}=\frac{1}{\sigma} \cdot\left[\phi\left(\frac{g}{k}\right) \cdot(1-\eta)-\rho\right] .
$$

Thus $\gamma_{L}$ differs from $\gamma$ by the absence of the term $1-\tau$ inside the brackets.

The dashed curve in figure 1 graphs $\gamma_{L}$ as a function of $g / y$ for the 
case of a Cobb-Douglas production function. As is apparent from equation (22), $\gamma_{L}$ is monotonically increasing in $g / y$ because a higher $g / y$ means a higher marginal product of capital, $\partial y / \partial k$. With a lumpsum tax, households respond to the higher return on capital by choosing a higher growth rate for consumption (and a higher saving rate; see fig. 2).

A comparison of equations (20) and (22) indicates that $\gamma_{p}$ contains the term $1-(g / y)$ where $\gamma_{L}$ contains the term $1-\eta$. Since $\eta=\phi^{\prime}$. $(g / y)$, productive efficiency $\left(\phi^{\prime}=1\right)$ implies $\eta=g / y$. Therefore, the terms $1-(g / y)$ and $1-\eta$ coincide at this point. It follows that lumpsum taxation supports the command optimum if $g / y$ is set optimally, so that $\phi^{\prime}=1 .^{4}$

If the expenditure share is set nonoptimally so that $\phi^{\prime} \neq 1$, the planning solution for consumption-contingent on this incorrect choice of $g / y$-does not coincide with the solution under lump-sum taxation. This result indicates that the income tax is not the only distortion in the model. I am uncertain whether the other distortion is economically interesting, but I shall now explain what it is.

An individual producer computes the marginal product, $\partial y / \partial k$, while holding constant the quantity of public services, $g$, that he receives from the government. This assumption is appropriate for some types of public services, and I maintain this assumption for now. But if the government sets a given expenditure ratio $g / y$, an increase in national product by one unit induces the government to raise the aggregate of its public services by $g / y$ units. Thus when an individual producer decides to raise his individual $k$ and $y$, he is indirectly causing the government to increase its aggregate spending. The effect on that individual's public services, which entered into his production function, would be negligible (under my assumption about how public services are provided) and can therefore be ignored. But it is nevertheless true, with $g / y$ fixed, that an individual's decision that

\footnotetext{
${ }^{4}$ This result under lump-sum taxation implies that the solution $\tau=g / y=\alpha$ is time consistent under income taxation and a Cobb-Douglas technology. Suppose that future governments will set the income tax rate, $\tau(t)=\alpha$, for all $t>0$. Then, for given $k(0)$, the current income tax rate, $\tau(0)$, is effectively a lump-sum tax. In particular, the current choice affects neither past investments (which cannot be undone) nor expected future tax rates (which matter for current and future investment). If the government could run budget surpluses and thereby accumulate assets, it would be attractive to choose a very high value of $\tau(0)$ and use the proceeds to finance future spending (which otherwise would require distorting income taxation). However, the balanced-budget constraint in eq. (11) rules out this possibility. Therefore, the government selects the current tax and expenditure ratio, $\tau(0)=g(0) / y(0)$, as it would under lump-sum taxation. But the solution to this problem is $\tau(0)=g(0) / y(0)=\alpha$. In the absence of the balanced-budget constraint, the government would have the usual incentive to effect capital levies, so that $\tau(t)=\alpha$ would no longer be time consistent. (Private investors would also anticipate these levies and act accordingly.) The result $\tau(t)=\alpha$ would then hinge on the government's ability (starting from time $t=-\infty$ ) to commit itself to a constant tax rate.
} 
raises national product by one unit causes the total of government purchases to expand by $g / y$ units. The effects depend on whether the size of the government is optimal. If so-namely, at the point $\phi^{\prime}=1$-a marginal change in government expenditures is just worth its cost. Hence there is no distortion, and the lump-sum tax result replicates the planning optimum, as noted before. But suppose that the government is too large, in the sense that $\phi^{\prime}<1$. Then the induced expansion of government expenditures constitutes a negative externality. On this count, each individual has too much incentive to expand individual output; in particular, in this model, each individual has too much incentive to save. Hence (for the Cobb-Douglas case), $g / y>\alpha$ implies $\gamma_{L}>\gamma_{p}$ in figure 1 and $s_{L}>s_{p}$ in figure 2 . Analogously, the incentive to expand individual output is too low when the government is too small $\left(\phi^{\prime}>1\right)$. Hence, $\gamma_{L}<\gamma_{p}$ and $s_{L}<s_{p}$ apply in this range.

Figures 1 and 2 also allow a comparison between lump-sum taxes (which could be consumption taxes in this model) and income taxes. At the point $g / y=\alpha$ (in the Cobb-Douglas case), the lump-sum tax generates the command optimum and is therefore superior to the income tax. For $g / y<\alpha$, the lump-sum tax comes closer than the income tax to the command optimum; therefore, the lump-sum tax would also be preferred here. However, for $g / y>\alpha$, the comparison becomes ambiguous because the lump-sum tax choices, $\gamma_{L}$ and $s_{L}$, are too large, while the income tax choices, $\gamma$ and $s$, are too small. For very large governments (i.e., $g / y$ well above $\alpha$ ), the outcome under income taxes can be superior to that under lump-sum taxes. The reason is that the income tax is an imperfect way to get individual producers to internalize the distortion described above. With $g / y>\alpha$, people have too great an incentive to expand output by an additional unit because the government is thereby induced to increase its expenditures by $g / y$ units. If government spending were worthless, the way to internalize this distortion would be to tax the individual's income at the rate $\tau=$ $g / y$. As $g / y$ gets well above its ideal value, $\alpha$, the return from more government spending, $\phi^{\prime}$, diminishes; that is, it becomes more nearly accurate that government spending is worthless at the margin. Therefore, the income tax becomes more nearly the right way to offset the negative externality, and the value $\gamma$ in figure 1 gets steadily closer to the value $\gamma_{p}$. Similarly, in figure $2, s$ and $s_{p}$ converge as $g / y$ approaches one.

\section{Tax Systems and Property Rights}

Within the framework of an income tax, the (average) marginal tax rate, $\tau$, can vary for a given expenditure ratio, $g / y$. For example, differences in the degree of graduation or in enforcement policies 
could generate these variations in $\tau$. If $\tau$ decreases, for a given $g / y$, the response is a movement in the direction from the solid to the dashed curve (i.e., from $\gamma$ to $\gamma_{L}$ ) in figures 1 and 2 . Hence, for given $g / y$, the rates of growth and saving increase.

From the standpoint of investors, enhanced property rights look like reductions in marginal tax rates. Therefore, an improvement in property rights also generates a shift in the direction from the solid to the dashed curve in figures 1 and 2. Hence, the rates of growth and saving again increase.

Many functions of government, such as maintenance of law and order and national security, help to sustain property rights. (Others, including some regulatory and legislative activities, have opposing effects.) An increase in spending, $g$, in areas that enhance property rights causes a reduction in the effective value of $\tau$ rather than a direct effect on the production function. However, the effects on growth and saving are similar to those for the productive government expenditures considered before. In particular, the relation of growth and saving rates to the amount of government expenditure devoted to the enforcement of property rights would resemble the solid curves shown in figures 1 and 2.

\section{An Alternative Specification for Public Services}

Thus far, each individual held fixed his quantity of public services, $g$, when considering a change in his quantity of capital, $k$, and output, $y$. This setting is appropriate for some public services but not for others. For example, for police and fire protection, and perhaps for national defense, the amount of public services that an individual receives is roughly proportional to the amount of property that the person has to protect. (Thompson [1974] argues that an increase in an individual's appropriable property makes the home country more attractive to foreign aggressors and thereby increases the home country's overall burden for providing national security.) These cases can be approximated by assuming that each individual holds constant his ratio of public services to output, $g / y$, rather than his level of public services.

With a flat-rate income tax at rate $\tau$, the individual's optimization problem now coincides with the planner's problem considered before. Hence (for the case in which public services appear directly in the production function), the decentralized choices lead to the growth rate $\gamma_{p}$ shown in figure 1 and the saving rate $s_{p}$ shown in figure 2 . The private choices lead to a Pareto optimum because the income tax at rate $\tau=g / y$ works like a user fee to internalize the effect of an 
individual's choices on his level of public services. In particular, a decision to raise $y$ by one unit (by an increase in $k$ ) leads to increases in own public services and taxes by $\tau$ units. Since individuals are effectively paying for the services they receive, a Pareto optimum results.

\section{Government Consumption Services}

I now return to the setting in which each individual holds constant his level of public services. But suppose that the government's expenditures also finance some services that enter into households' utility functions. I assume that total spending per household is $g+h$, where the quantity $h$ represents the government's consumption services. The utility function for each household is now

$$
u(c, h)=\frac{\left(c^{1-\beta} \cdot h^{\beta}\right)^{1-\sigma}-1}{1-\sigma},
$$

where $0<\beta<1$. The household's overall utility is still given by equation (1), except that $u(c, h)$ replaces $u(c)$ in the integral.

I still assume a flat-rate income tax, so that the government's budget constraint is

$$
T=\left(\tau_{g}+\tau_{h}\right) \cdot y,
$$

where $\tau_{g}=g / y$ is the government's expenditure ratio for productive services, and $\tau_{h}=h / y$ is the ratio for consumption services.

Households' decentralized choices for consumption and saving (with $g$ and $h$ taken as given) now lead to the growth rate

$$
\gamma_{h}=\frac{1}{\sigma} \cdot\left[\left(1-\tau_{g}-\tau_{h}\right) \cdot \phi\left(\frac{g}{k}\right) \cdot(1-\eta)-\rho\right] .
$$

This expression modifies equation (13) in a straightforward manner. The dotted curve in figure 3 shows the relation between $\gamma_{h}$ and the share of productive government spending, $\tau_{g}=g / y$, taking account of the positive value of $\tau_{h}=h / y$. The growth rate lies uniformly below the value $\gamma$, shown by the solid curve, that would have been chosen if $\tau_{h}=0$. Figure 4 shows the corresponding saving rates, $s_{h}$ and $s$.

For a given $\tau_{h}$ and a Cobb-Douglas production function, it is easy to show that the value of $\tau_{g}=g / y$ that maximizes $\gamma_{h}$ in equation (25) is $\alpha\left(1-\tau_{h}\right)$. In other words, the growth-maximizing share of productive government spending is smaller if the government is also using the income tax to finance other types of spending. However, this choice turns out not to maximize the utility attained by the representative household.

Suppose that each household's utility function is given by equation (23) and that $\tau_{g}=g / y$ and $\tau_{h}=h / y$ are set to maximize the overall 


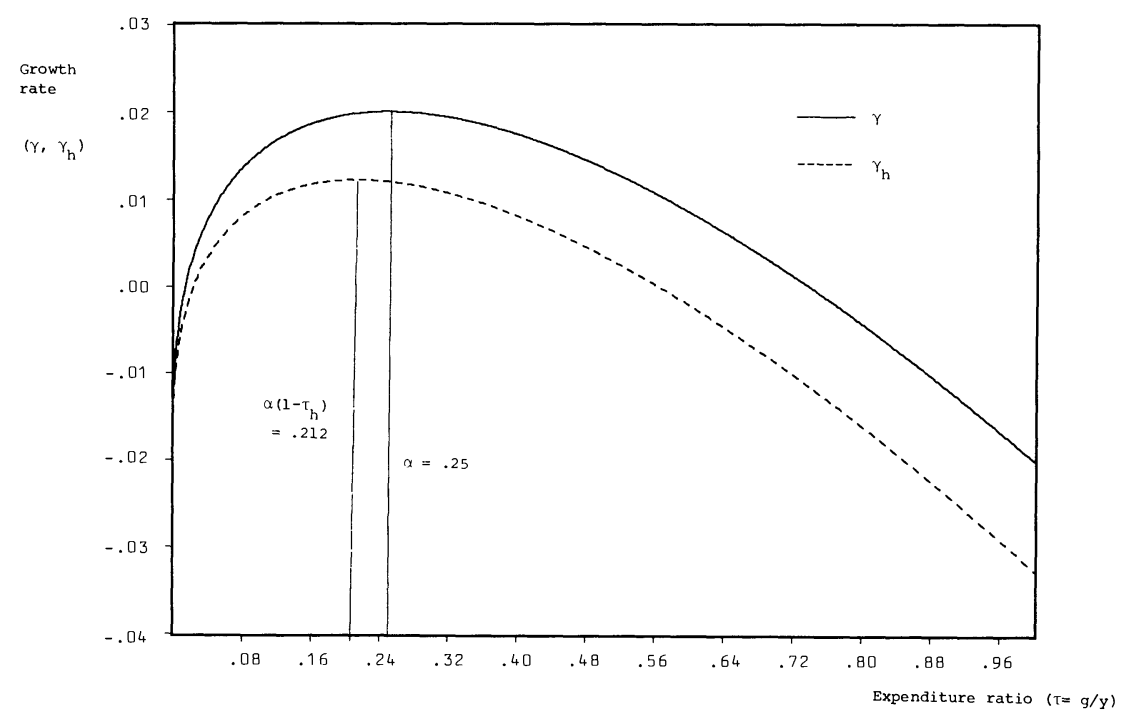

FIG. 3.-Growth when the government also provides consumption services. $\gamma$ is from eq. (13) and $\gamma_{h}$ from eq. (25). The graph of $\gamma_{h}$ assumes $\tau_{h}=.15$. Other parameter values are from fig. 1 .

utility attained by the representative household in the form of equation (1). (I again restrict attention to expenditure and tax rates that are constant over time.) The effects of the tax rates on $\gamma_{h}$ are shown in equation (25). As before, it is possible to determine the initial level of consumption, $c(0)$, and thereby calculate the entire path of consumption as $c(t)=c(0) \cdot e^{\gamma_{h} t}$. The path of the government's consumption services is given by $h(t)=\tau_{h} \cdot y(t)=\tau_{h} \cdot y(0) e^{\gamma_{h} t}$. With these results, it is feasible to relate the attained utility, $U$, to the expenditure ratios $\tau_{g}=$ $g / y$ and $\tau_{h}=h / y$. There are then two first-order conditions corresponding to the maximization of $U$. Combining these conditions for the case of a Cobb-Douglas production function leads to the familiar result: $\tau_{g}=g / y=\alpha$. That is, as long as $\tau_{h}=h / y$ is also chosen optimally, the optimal ratio for productive government expenditures is the same as before. Namely, the criterion is still productive efficiency, so that $\phi^{\prime}=1$ and $g / y=\alpha$.

\section{Self-interested Government}

Thus far, I assumed that the government was benevolent and therefore sought to maximize the utility attained by the representative household. I now consider the alternative that the government is run by an agent who has no electoral constraints and seeks to maximize his own utility. 


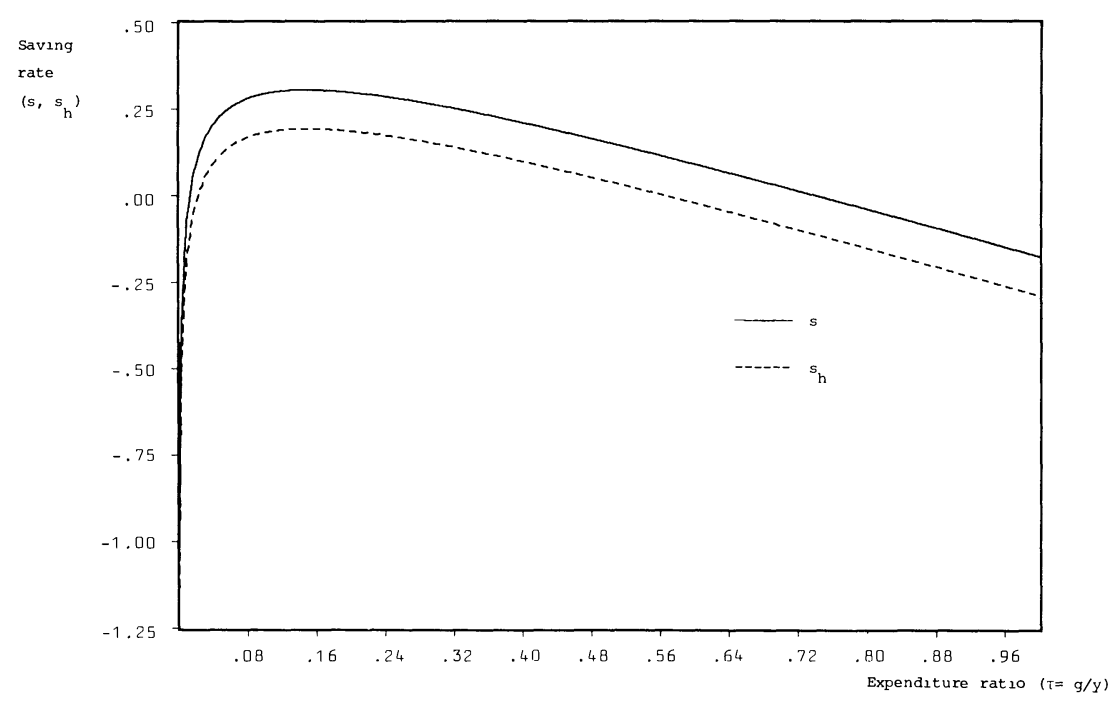

FIG. 4.- Saving rate when the government also provides consumption services. $s$ is from eq. (16); $s_{h}=\gamma_{h} \cdot(k / y)$, where $\gamma_{h}$ is from eq. (25); and $\tau_{h}=.15$. Other parameter values are from fig. 1 .

Return to the setting in which all government expenditures, $g$, serve as productive inputs for private producers. The government still uses a flat-rate income tax, but instead of automatically balancing the budget, the government can earn the net revenue

$$
c_{g}=\left(\tau-\frac{g}{y}\right) \cdot y,
$$

where the expenditure ratio $g / y$ can differ from the income tax rate $\tau$. The government agent uses his net revenue to purchase the quantity of consumer goods, $c_{g}$. The agent receives utility from consumption in the same manner as any household; that is, the flow of utils is $u\left(c_{g}\right)$ from equation (2), and the overall attained utility, $U$, is given by the integral in equation (1). In addition, the government agent has the same discount rate, $\rho$, as each household.

With constant values for $\tau$ and $g / y$, the privately determined growth rate is still the value $\gamma$ from equation (13). The only difference is that $g / y$ no longer equals $\tau$. The government agent's consumption is $c_{g}(t)=$ $[\tau-(g / y)] \cdot y(0) e^{\gamma t}$. Therefore, it is possible to write the agent's attained utility as a function of $\tau$ and $g / y$. For a Cobb-Douglas production function, the two first-order conditions for maximization of the agent's utility lead to the results

$$
\tau>\frac{g}{y}=\alpha .
$$


The optimal expenditure rate $g / y$ equals $\alpha$, as in previous models; that is, the productive-efficiency condition, $\phi^{\prime}=1$, still holds. Since the choice of $g / y$ is mainly one of efficient production, the self-interested government chooses the same value as the benevolent government. Basically, the government agent sets $g / y=\alpha$ to maximize the tax base that he has to work with. Then he is also in the position to set $\tau>g / y$ to secure the net flow of revenue, $c_{g}$.

The results in this section parallel those in the preceding one. In effect, the government agent's consumption, $c_{g}$, plays the same role that the government's consumption services, $h$, played in the previous model. In both cases the presence of these consumption flows does not upset the conditions for productive efficiency, which imply (for Cobb-Douglas technology) that the government's productive expenditures are the fraction $\alpha$ of total output. However, the ratio of government revenues to output exceeds $\alpha$ in both situations: in one case to provide consumption to the government agent and in the other to provide government consumption services to each household.

\section{Some Empirical Implications}

The theory has implications for relations between the size of government and the rates of growth and saving. Because the analysis applies to steady-state growth paths, the natural empirical application would be to differences in average performance across countries over long periods of time.

As is usual in empirical investigations, the hypothesized effects of government policy are easier to assess if the government's actions can be treated as exogenous. That is, the results are simple if governments randomize their actions and thereby generate useful experimental data. In this case, variations in the share of productive government expenditures in GDP, $g / y$, affect the growth and saving rates, $\gamma_{h}$ and $s_{h}$, as shown by the dashed curves in figures 3 and 4 , respectively. (The precise curves apply with a proportional income tax and CobbDouglas production function and in settings in which individuals treat their own allocations of public services, $g$ and $h$, as given.) As suggested before, productive government spending would include the resources devoted to property rights enforcement, as well as activities that enter directly into production functions. Countries could be arrayed along the horizontal axes by the size of $g / y$, and the responses of $\gamma$ and $s$ would be nonmonotonic, as shown in the figures.

An increase in the share of nonproductive government expenditures, say $h / y$ in the model of Section $\mathrm{V}$, leads to the types of shifts shown by the movements from the solid to the dashed curves in figures 3 and 4 . For a given value of $g / y$, an increase in $h / y$ lowers the 
growth and saving rates. These effects arise because a higher $h / y$ has no direct effect on private-sector productivity, but does lead to a higher income tax rate. Since individuals retain a smaller fraction of their returns from investment, they have less incentive to invest, and the economy tends to grow at a lower rate.

The predictions are similar for any other differences across countries that imply that private investors get to retain a smaller fraction of their returns from investment. For example, if $g / y$ is held fixed, an increase in the average marginal tax rate or an exogenous worsening of property rights would tend to lower the growth and saving rates.

Aside from problems of measuring public services and the rates of growth and saving, the empirical implementation of the model is complicated by the endogeneity of the government. Within the theoretical model (and with a Cobb-Douglas production function), the government sets the share of productive expenditures, $g / y$, to ensure productive efficiency $\left(\phi^{\prime}=1\right)$. Therefore, instead of being arrayed along the horizontal axes in figures 3 and 4, each government would operate at the same point, $g / y=\alpha$. Within this framework of optimizing governments, cross-sectional variations in $g / y$ arise only if $\alpha$ differs from country to country.

The parameter $\alpha$, which measures the productivity of public services relative to private services, could vary across countries for a number of reasons. These include geography, the share of agricultural production, urban density, and so on. For present purposes it is unnecessary to predict how any specific element would affect $\alpha$, and therefore $g / y$, for an optimizing government. As long as the variations in $\alpha$ are independent of the overall level of productivity, ${ }^{5}$ the model predicts how the induced variations in $g / y$ will correlate with those in $\gamma$. The result is that a rise in $\alpha$, and hence in $g / y$, will reduce $\gamma .{ }^{6}$ The intuition is that an increase in $\alpha$ means a shift in relative productivity toward the factor $g$ that has to be financed by a distorting tax. It is for this reason that a higher $\alpha$ correlates negatively with $\gamma$. The more general conclusion is that $g / y$ and $\gamma$ would show little correlation across countries because each government goes to the point at which the marginal effect of $g / y$ on $\gamma$ is close to zero.

For government expenditures that provide only consumption services, the implications are more straightforward. Variations in the expenditure share for government consumption, $h / y$-viewed as generated from differences in preferences for public versus private ser-

\footnotetext{
${ }^{5}$ For a Cobb-Douglas production function, $y / k=A(g / k)^{\alpha}$ from eq. (10). The condition $g / k=(g / y) \cdot(y / k)$ implies $y / k=A^{1 /(1-\alpha)}(g / y)^{\alpha /(1-\alpha)}$. Therefore, the parameter $A^{1 /(1-\alpha)}$ indicates the level of private productivity, $y / k$, for a given value of $g / y$. The assumption is that cross-sectional variations in $A^{1 /(1-\alpha)}$ are independent of those in $\alpha$.

${ }^{6}$ The saving rate $s$ also declines if $\gamma>0$.
} 
vices (the parameter $\beta$ in eq. [23]) — correlate negatively with the growth and saving rates.

\section{Empirical Results on Government and Growth}

The literature includes a number of empirical studies on the relationship between government and economic growth. Kormendi and Meguire (1985) studied 47 countries in the post-World War II period, using data on total government "consumption" expenditures and other variables from International Financial Statistics. This measure of government spending excludes public investment and transfers but includes most expenditures on defense and education. Although the category is called consumption, it does not necessarily followespecially for defense and education-that these public services enter mainly into utility functions rather than into production functions or as influences on property rights. Using data for each country averaged over roughly 20-year periods, Kormendi and Meguire found no significant relation between average growth rates of real GDP and average growth rates or levels of the share of government consumption spending in GDP (p. 147).

Grier and Tullock (1987) extended the Kormendi-Meguire form of analysis to 115 countries, using data on government consumption and other variables from Summers and Heston (1984). The concept of government spending is the same as that employed by Kormendi and Meguire. The Grier-Tullock study was a pooled cross-section, timeseries analysis, using data averaged over 5 -year intervals. They found a significantly negative relation between the growth of real GDP and the growth of the government share of GDP, although most of the relation derived from the 24 OECD countries (their tables 1 and 2).

Landau (1983) studied 104 countries on a cross-sectional basis, using an earlier form of the Summers-Heston data. He found significantly negative relations between the growth rate of real GDP per capita and the level of government consumption expenditures as a ratio to GDP (table 1). His definition of government consumption is again the same as those used above. However, his regressions held constant a measure of investment in education, which would be one component of an economy's broadly defined investment. Since one channel for a negative effect of more government on growth involves a reduction in investment, the interpretation is different if a component of investment is held constant.

Barth and Bradley (1987, table 1) found a negative relation between the growth rate of real GDP and the share of government consumption spending for 16 OECD countries in the period 1971- 
83. They also found that the share of government investment in GDP had a statistically insignificant effect on growth, although the point estimate was positive. However, the last estimate applies when the ratio of private investment to GDP is held constant.

In a recent study of 98 countries in the post-World War II period (Barro 1989), I modified the Summers-Heston (1988) data on government consumption. For the period 1970-85, I subtracted the ratios to GDP of government spending on defense and education from the ratios reported by Summers and Heston. ${ }^{7}$ The average value for each country from 1970 to 1985 , denoted by $g^{c} / y$, was used as a proxy for the government spending ratio, $h / y$, that enters directly into the utility function in the theoretical model. The identification of $g^{c}$ with $h$ is imperfect; for example, police services (a component of $g^{c}$ ) would influence property rights and thereby affect private investment and growth.

I also measured the ratio of real public gross investment to real GDP, denoted by $g^{l} / y$. This public investment corresponds to a stock of public capital, $k^{g}$, which generates a flow of services that I view as comparable to the productive services $g$ in the theory. Thus this empirical measure identifies $g$ with "infrastructure services," such as transportation, water, electric power, and so on (although hospitals and schools are also components of public capital). As with the identification of $g^{c}$ with $h$, the identification of the flow of services from public capital with productive government services is imperfect.

In the model, where public capital is combined with private capital (because public and private production are viewed as governed by the same production function), the "public capital stock" corresponds to the fraction of the total stock, $k$, that produces the public services; that is, $k^{g}=(g / y) \cdot k$. Hence, $g / y$ can be measured by the ratio $k^{g} / k$. Since data on $k^{g}$ and $k$ are unavailable for most countries, I instead approximated $k^{g} / k$ by the ratio of gross investments, $g^{\imath} / i$, where $i$ is the sum of private and public investment. The assumptions here are that $g / y$ is constant over time for a single country, and public and private capital have the same depreciation rates. According to the theory, the relation of the growth rate $\gamma$ to $g^{2} / i$ depends on how governments behave. If governments optimize (go close to the point of maximal growth), $\gamma$ and $g^{2} / i$ would show little cross-sectional correlation. On the other hand, the association would be positive (or negative) if governments typically choose too little (or too much) of productive public services.

\footnotetext{
${ }^{7}$ For defense and education, the ratios were nominal spending relative to nominal GDP, whereas the Summers-Heston figures are real spending relative to real GDP. The implicit assumption (generated by lack of an alternative) is that the appropriate deflator for defense and education is the GDP deflator.
} 
For the 98 countries for which $g^{c} / y$ was measured (Barro 1989, table $1)$, a regression of the average annual growth rate of real per capita GDP from 1960 to 1985 on a set of explanatory variables ${ }^{8}$ yielded an estimated coefficient on $g^{c} / y$ of -.12 (standard error $=.03$ ). Thus there is an indication that an increase in resources devoted to nonproductive (but possibly utility-enhancing) government services is associated with lower per capita growth.

For the 76 countries for which data on public investment were available, the estimated coefficient on $g^{2} / i$ was .014 (s.e. $=.022$ ). Thus the point estimate was positive but insignificantly different from zero. This result is consistent with the hypothesis that the typical country comes close to the quantity of public investment that maximizes the growth rate.

If the ratio of public investment to GDP, $g^{2} / y$, replaces $g^{2} / i$ as an explanatory variable in the growth equation, the estimated coefficient is again positive but insignificant: .13 (s.e. $=.10$ ). Moreover, if the variable $i / y$ is also included as a regressor, the estimated coefficient of $i / y$ is .073 (s.e. $=.039$ ), and that for $g^{2} / y$ becomes -.015 (s.e. $=.119$ ). From the standpoint of the theory, the positive coefficient on $i / y$ can be interpreted as the common influence of omitted variables on investment and growth. In any event, once the total investment ratio $i / y$ is held constant, there is no separate effect on growth from the breakdown of total investment between private and public components.

These empirical results are representative of ongoing research on the determinants of economic growth across countries. Aside from the role of government, this research is currently focusing on the effects of human capital, market distortions, and political stability. Results of this research will be reported in subsequent papers.

\section{References}

$\rightarrow$ Arrow, Kenneth J. "The Economic Implications of Learning by Doing." Rev. Econ. Studies 29 (June 1962): 155-73.

Arrow, Kenneth J., and Kurz, Mordecai. Public Investment, the Rate of Return, and Optimal Fiscal Policy. Baltimore: Johns Hopkins Univ. Press (for Resources for the Future), 1970.

Aschauer, David A. "Is Public Expenditure Productive?" Manuscript. Chicago: Fed. Reserve Bank Chicago, March 1988.

Barro, Robert J. "Economic Growth in a Cross Section of Countries." Working Paper no. 3120. Cambridge, Mass.: NBER, September 1989.

Barth, James R., and Bradley, Michael D. "The Impact of Government

\footnotetext{
${ }^{8}$ The regression also included the initial (1960) values of real per capita GDP and school enrollment rates (intended as proxies for initial human capital) and variables that measure political stability and market distortions. See Barro (1989) for details.
} 
Spending on Economic Activity." Manuscript. Washington: George Washington Univ., 1987.

$\rightarrow$ Becker, Gary S., and Barro, Robert J. "A Reformulation of the Economic Theory of Fertility." Q.J.E. 103 (February 1988): 1-25.

Becker, Gary S.; Murphy, Kevin M.; and Tamura, Robert. "Human Capital, Fertility, and Economic Growth." J.P.E., this issue.

$\rightarrow$ Cass, David. "Optimum Growth in an Aggregative Model of Capital Accumulation." Rev. Econ. Studies 32 (July 1965): 233-40.

Domar, Evsey D. "Expansion and Employment." A.E.R. 37 (March 1947): $34-55$.

Grier, Kevin B., and Tullock, Gordon. "An Empirical Analysis of Crossnational Economic Growth, 1950-1980." Manuscript. Pasadena: California Inst. Tech., December 1987.

Harrod, Roy F. Towards a Dynamic Economics: Some Recent Developments of Economic Theory and Their Application to Policy. London: Macmillan, 1948.

Koopmans, Tjalling C. "On the Concept of Optimal Economic Growth." In The Econometric Approach to Development Planning. Amsterdam: NorthHolland, 1965.

Kormendi, Roger C., and Meguire, Philip G. "Macroeconomic Determinants of Growth: Cross-Country Evidence." J. Monetary Econ. 16 (September 1985): 141-63.

$\rightarrow$ Landau, Daniel L. "Government Expenditure and Economic Growth: A Cross-Country Study.” Southern Econ. J. 49 (January 1983): 783-92.

$\rightarrow$ Lucas, Robert E., Jr. "On the Mechanics of Economic Development." J. Monetary Econ. 22 (July 1988): 3-42.

Ramsey, Frank P. “A Mathematical Theory of Saving.” Econ. J. 38 (December 1928): 543-59.

Rebelo, Sergio. "Long-Run Policy Analysis and Long-Run Growth." J.P.E. (1991), in press.

$\rightarrow$ Romer, Paul M. "Increasing Returns and Long-Run Growth." J.P.E. 94 (October 1986): 1002-37.

- "Capital Accumulation in the Theory of Long Run Growth." In Modern Business Cycle Theory, edited by Robert J. Barro. Cambridge, Mass.: Harvard Univ. Press, 1989.

—. "Endogenous Technological Change." J.P.E., this issue.

$\rightarrow$ Samuelson, Paul A. "The Pure Theory of Public Expenditure." Rev. Econ. and Statis. 36 (November 1954): 387-89.

$\rightarrow$ Solow, Robert M. "A Contribution to the Theory of Economic Growth." Q.J.E. 70 (February 1956): 65-94.

$\rightarrow$ Summers, Robert, and Heston, Alan. "Improved International Comparisons of Real Product and Its Composition: 1950-1980." Rev. Income and Wealth 30 (June 1984): 207-62.

$\longrightarrow \rightarrow$. "A New Set of International Comparisons of Real Product and Price Levels: Estimates for 130 Countries, 1950-1985." Rev. Income and Wealth 34 (March 1988): 1-25.

$\rightarrow$ Thompson, Earl A. "Taxation and National Defense." J.P.E. 82 (July/August 1974): 755-82. 